Jurnal Artikel

\title{
Efek Variasi Suhu Larutan Media Pendingin Terhadap Lapisan Deposit Las Elektroda E7018/HV350 Pada Material Baja Karbon
}

\author{
Sopiyan $^{1 *}$, Syaripuddin ${ }^{1}$, Syamsuir $^{1}$ \\ Teknik Mesin, Fakultas Teknik, Universitas Negeri Jakarta \\ ${ }^{1}$ sopiyan@unj.ac.id , ${ }^{2}$ syaripuddin_andre@yahoo.com , ${ }_{3}$ syam_tjg@yahoo.com \\ *Corresponding author - Email : sopiyan@unj.ac.id
}

Artkel Info - : Received : 30 Aug 2020; Revised : 2 Sep 2020 ; Accepted: 4 Sep 2020

\begin{abstract}
Penelitian ini bertujuan untuk mengetahui fenomena kekerasan yang terjadi pada deposit hasil pengelasan. Pada penelitian ini dilakukan proses pengelasan secara multilapis dengan menggunakan dua elektroda yaitu HV 350 dan E 7018. Setelah selesai pengelasan kemudian spesimen dilakukan perlakukan panas dengan menggunakan dua variasi suhu larutan pendingin yaitu $15^{\circ} \mathrm{C}$ dan $30^{\circ} \mathrm{C}$. Dari hasil uji keras diketahui bahwa suhu $15{ }^{\circ} \mathrm{C}$ terbukti menghasilkan kekerasan lebih tinggi jika dibandingkan dengan tanpa perlakuan (NT) maupun perlakuan panas dengan suhu $30^{\circ} \mathrm{C}$.
\end{abstract}

Kata kunci: $H V$ 350, E 7018, suhu

\section{Abstract}

This study aims to determine the phenomenon of hardness that occurs in deposits of welding results. In this research, a multi-layered welding process was carried out using two electrodes, namely $H V 350$ and $E$ 7018. After the welding was finished, the specimens were treated with heat using two variations of the cooling solution temperature, $15{ }^{\circ} \mathrm{C}$ and $30{ }^{\circ} \mathrm{C}$. From the results of hard tests it is known that the temperature of $15^{\circ} \mathrm{C}$ is proven to produce higher hardness when compared with without treatment (NT) or heat treatment with a temperature of $30^{\circ} \mathrm{C}$.

Keywords: HV 350, E 7018, temperature

\section{PENDAHULUAN}

Pada kegiatan yang berhubungan dengan konstruksi baik bangunan maupun mesin mayoritas melibatkan baja sebagai komponen utamanya (Purwanto, 2011). Akan tetapi baja memiliki jenis yang beragam. Jika ditinjau dari kadar karbonnya baja dibedakan menjadi baja karbon rendah, menengah dan tinggi. Jenis-jenis baja tersebut umumnya digunakan sesuai dengan kebutuhan sesuai dengan karakteristik mekanik baja.

Penggunaan baja pada alat berat terutama excavator sering mengalami problematika seperti kurangnya tingkat keausan, terutama pada bucket-nya.
Sehingga perlu dilakukan improvisasi untuk meningkatkan kekerasan dari material baja tersebut. Karena dengan penggantian komponen otomatis akan membutuhkan waktu sehingga kendaraan otomatis tidak beroperasi. Hal ini dapat merugikan bagi perusahaan.

Untuk meningkatkan kekerasan dari suatu material baja dapat dilakukan dengan heat treatment dengan metode quenching (Saefuloh, 2018). Media quenching yang banyak digunakan saat ini adalah air karena ketersediaanya yang sangat berlimpah. Sehingga sangat murah dan tidak membebani produktiftas perusahaan (Nugroho \& Haryadi, 2005). Suhu air sebagai media quenching juga berperan 
penting dalam meningkatkan kekerasan dari baja. Air es terbukti dapat meningkatkan kekerasan baja karbon sedang (Murtiono, 2012).

Ketika melakukan proses heat treatment diperlukan beberapa parameter agar hasil yang didapatkan maksimal. Semakin lama holding time maka akan semakin meningkatkan nilai kekerasan (Dwiyati, Hutomo, \& Susetyo, 2019). Akan tetapi hal ini akan menambah biaya, karena proses pemanasan dalam tungku yang semakin lama.

Selain metode heat treatment dengan queching, upaya meningkatkan kekerasan dari material juga dapat dilakukan dengan proses hardfacing dengan SMAW. Beberapa ketersedian elektroda pada proses hardfacing adalah seperti HV 350 (Sopiyan, Susetyo, \& Syamsuir, 2018), HV 450 (Susetyo, Kholil, \& Fatihuddin, 2019) dan HV 600 (Susetyo, Basori, \& Maryanto, 2020). Selain dari elektroda tersebut, E7018 juga memiliki kekutan tarik yang relatif tinggi yaitu sekitar 46,73 $\mathrm{kgf} / \mathrm{mm}^{2}$ (Azwinur \& Muhazir, 2019). Sehingga kombinasi pengelasan dengan menggunakan elektroda hardfacing dan E7018 perlu dilakukan untuk melihat fenomena kekerasan yang terbentuk.

Oleh karena itu dalam penelitian kali ini baja karbon rendah yang telah dilapisi oleh E7018/E7018, dan E7018/HV 350 dipanaskan sampai temperatur $1000^{\circ} \mathrm{C}$ dan ditahan sampai 10 menit lalu dilakukan pendinginan secara cepat (quenching) dengan variasi suhu media pendingin untuk meningkatkan kekerasan.

\section{METODOLOGI}

Metodologi penelitian ini adalah sebagai berikut

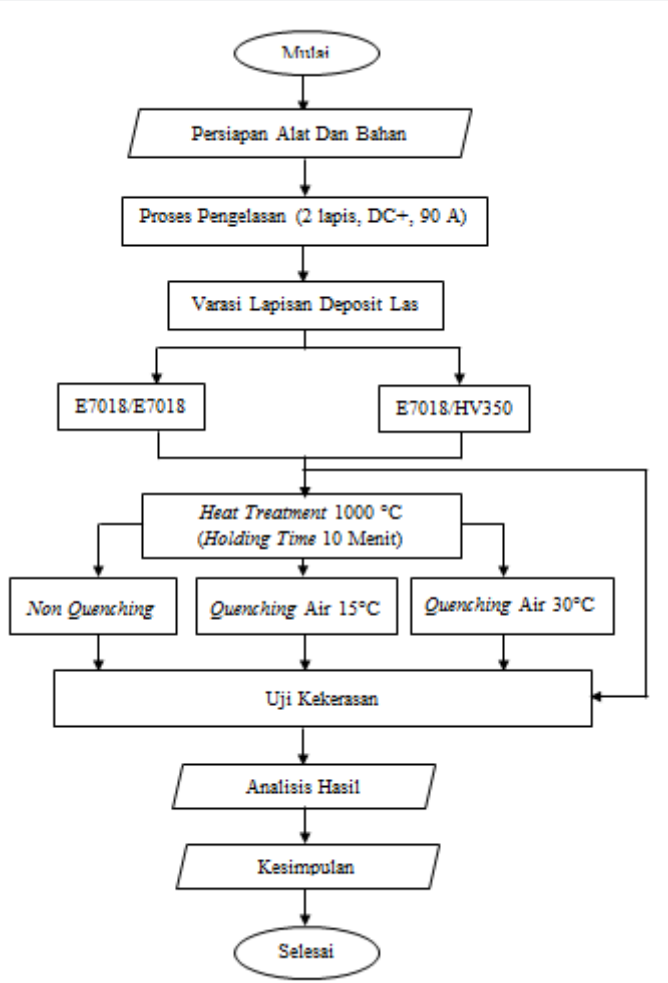

Gambar 2.1 Metodologi Penelitian

Dari gambar 2.1 dapat dijelaskan bahwa proses pengelasan dilakukan menggunakan elektroda E7018 dan HV 350 secara multilapis dengan polaritas DC + dan arus 90A. Dari spesimen yang telah dilakukan pengelasan kemudian dilakukan proses pemanasan dalam tungku selama 10 menit dengan temperatur $1000^{\circ} \mathrm{C}$. Setelah selesai dipanaskan kemudian spesimen dilakukan pendinginan cepat dengan dua variasi suhu larutan pendingin (air) yaitu $15^{\circ} \mathrm{C}$ dan $30^{\circ} \mathrm{C}$. Setelah selesai kemudian spesimen dilakukan uji kekerasan vickers untuk mengetahui nilai kekerasan yang terbentuk.

\section{HASIL DAN PEMBAHASAN}

Pada tabel 3.1 dapat terlihat data hasil uji kekerasan vickers dengan menggunakan beban 5kgf. Pengambilan data dilakukan sebanyak 5 kali kemudian dirata-ratakan hasilnya. 
Tabel 3.1 Hasil Uji Kekerasan E7018/E7018

\begin{tabular}{cccc}
\hline No & $\mathrm{NT}(\mathrm{VHN})$ & $15^{\circ} \mathrm{C}(\mathrm{VHN})$ & $30^{\circ} \mathrm{C}(\mathrm{VHN})$ \\
\hline 1 & 187.6 & 304.3 & 288.8 \\
2 & 194.2 & 321.2 & 286.1 \\
3 & 227 & 322.3 & 284.9 \\
4 & 213.9 & 294.6 & 268.8 \\
5 & 226.1 & 297.6 & 275.9 \\
$\begin{array}{l}\text { Rata- } \\
\text { Rata } \\
(\text { VHN })\end{array}$ & 209.76 & 308 & 280.9 \\
\hline \hline
\end{tabular}

Berdasarkan tabel 3.1, nilai rata-rata kekerasan dibuat grafik agar mudah dilakukan pembandingan antara spesimen $\mathrm{NT}, 15^{\circ} \mathrm{C}$ dan $30^{\circ} \mathrm{C}$.

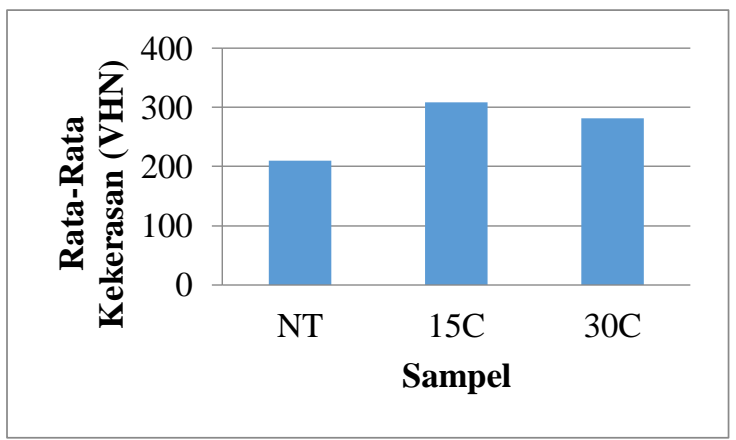

Gambar 3.1 Uji Kekerasan E 7018/ E 7018

Berdasarkan gambar 3.1 dapat terlihat semakin rendah temperatur air maka akan semakin meningkatkan kekerasan dari suatu material. Hal ini sesuai dengan penelitian yang dilakukan oleh murtiono, dimana melakukan proses quenching dengan air es (Murtiono, 2012). Elektroda jenis AWS E7018 juga cukup menjanjikan jika dilihat dari segi kekerannya, karena ketika di quenching dengan air $15^{\circ} \mathrm{C}$ dapat menghasilkan kekerasan sebesar 308 VHN. Kekerasan yang dihasilkan oleh E7018 tanpa perlakuan panas adalah 209,76 VHN kurang lebih sama dengan penelitian yang dilakukan oleh penelitian sebelumnya (Shomad \& Mushfi, 2017).

Pada tabel 3.2 dapat terlihat data hasil uji kekerasan vickers dengan menggunakan beban 5kgf. Pengambilan data dilakukan sebanyak 5 kali kemudian dirata-ratakan.
Tabel 3.2 Hasil Uji Kekerasan E 7018/HV350

\begin{tabular}{cccc}
\hline No & NT (VHN) & $15^{\circ} \mathrm{C}(\mathrm{VHN})$ & $30^{\circ} \mathrm{C}(\mathrm{VHN})$ \\
\hline 1 & 311.2 & 381.4 & 373.7 \\
2 & 283.4 & 403.9 & 400.7 \\
3 & 295.7 & 428.4 & 413.1 \\
4 & 324.4 & 405 & 353.2 \\
5 & 303.4 & 437.6 & 388.9 \\
$\begin{array}{l}\text { Rata- } \\
\text { Rata } \\
\text { (VHN) }\end{array}$ & 303.62 & 411.26 & 385.92 \\
\hline \hline
\end{tabular}

Berdasarkan tabel 3.2, nilai rata-rata kekerasan dibuat grafik agar mudah dilakukan pembandingan antara spesimen $\mathrm{NT}, 15^{\circ} \mathrm{C}$ dan $30^{\circ} \mathrm{C}$.

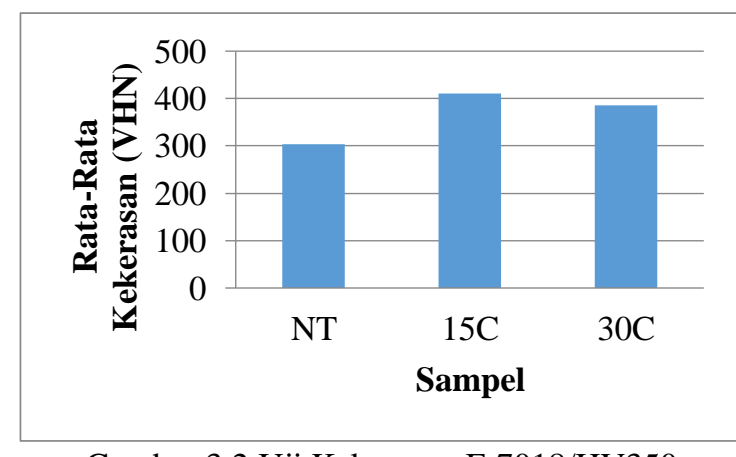

Gambar 3.2 Uji Kekerasan E 7018/HV350

Berdasarkan gambar 3.2 dapat terlihat semakin rendah temperatur air maka akan semakin meningkatkan kekerasan dari suatu material. Selain itu hasil yang didapat juga lebih keras jika dibandingkan dengan penelitian sebelumnya dimana arus yang digunakan lebih tinggi namun tidak dilakukan proses quenching (Sopiyan et al., 2018). Karena pada penelitian sebelumnya hanya dilakukan proses pengelasan satu lapis menggunakan elektroda HV 350.

\section{KESIMPULAN}

Dari hasil uji keras diketahui bahwa suhu $15^{\circ} \mathrm{C}$ terbukti menghasilkan kekerasan lebih tinggi jika dibandingkan dengan tanpa perlakuan (NT) maupun perlakuan panas dengan suhu $30^{\circ} \mathrm{C}$. 


\section{DAFTAR PUSTAKA}

Azwinur, \& Muhazir. (2019). Pengaruh Jenis Elektroda Pengelasan Smaw Terhadap Sifat Mekanik Material SS400. Jurnal Polimesin, 17(1), 1925.

Dwiyati, S. T., Hutomo, M. B. P., \& Susetyo, F. B. (2019). Pengaruh Variasi Holding Time Dan Media Quenching Terhadap Nilai Kekerasan Baja Dengan Kadar Karbon 0,192wt.\%. Jurnal Konversi Energi Dan Manufaktur, 6(1), 37-43.

Murtiono, A. (2012). Pengaruh Quenching dan tempering Terhadap kekerasan dan kekuatan tarik Serta Struktur Mikro baja karbon Sedang Untuk mata pisau pemanen sawit. $E$ Dinamis, II(2).

Nugroho, S., \& Haryadi, G. D. (2005). Pengaruh Media Quenching Air Tersirkulasi (Circulated Water) Terhadap Struktur Mikro Dan Kekerasan Pada Baja Aisi 1045. Rotasi, 7(1), 19-23.

Purwanto, H. (2011). Analisa Quenching Pada Baja Karbon Rendah Dengan Media Solar. Momentum, 7(1), 3640.
Saefuloh, I. (2018). Pengaruh Proses Quenching Dan Tempering Terhadap Sifat Mekanik Dan Struktur Mikro Baja Karbon Rendah Dengan Paduan Laterit. FLYWHEEL: Jurnal Teknik Mesin Untirta, 1(1), 56-64.

Shomad, M. A., \& Mushfi, M. S. (2017). Analisis pengaruh variasi elektroda las E6013 dan E7018 terhadap kekuatan tarik dan kekerasan pada bahan baja SS 400. Dinamika Teknik Mesin, 7(2), 73-79.

Sopiyan, Susetyo, F. B., \& Syamsuir. (2018). Pengaruh Arus Terhadap Kenyamanan Welder, Cacat Las Dan Kekerasan Hasil Hardfacing Baja Karbon. Jurnal Kajian Teknik Mesin, 3(2), 57-107.

Susetyo, F. B., Basori, I., \& Maryanto, D. (2020). Pengaruh Direct Dan InDirect Quenching Dengan Media Air Terhadap Kekerasan Hasil Hardfacing Baja Karbon. Jurnal Asiimetrik, 2(2), 125-131.

Susetyo, F. B., Kholil, A., \& Fatihuddin, M. (2019). Efek Polaritas Dan Media Pendingin Terhadap Nilai Kekerasan Permukaan Hardfacing Baja Karbon Rendah. Jurnal Konversi Energi Dan Manufaktur, 6(1), 1-5. 